\title{
Cochlear Implantation Using the Endomeatal Approach in a Child with a Extremely Hypoplastic Mastoid
}

\author{
Byung Yoon Joo and Sung Wook Jeong \\ Department of Otolaryngology-Head and Neck Surgery, Dong-A University College of Medicine, Busan, Korea
}

\author{
유양동 발달이 불량한 소아 환자에게 시행한 경외이도 접근법을 이용한 인공와우이식 \\ 주 병 윤 · 정 성 욱 \\ 동아대학교 의과대학 이비인후과학교실
}

\author{
Received October 14, 2015 \\ Revised December 10, 2015 \\ Accepted December 29, 2015 \\ Address for correspondence \\ Sung Wook Jeong, MD, PhD \\ Department of Otolaryngology- \\ Head and Neck Surgery, \\ Dong-A University College of Medicine, \\ 26 Daesingongwon-ro, \\ Seo-gu, Busan 49201, Korea \\ Tel $+82-51-240-5423$ \\ Fax $+82-51-253-0712$
}

E-mailsu0305@lycos.co.kr
The classic surgical technique for cochlear implantation was first introduced by House in 1961. This technique includes a mastoidectomy and a posterior tympanotomy, which has been most widely used for cochlear implantation. However, this approach may result in the injury of the chorda tympani nerve or the facial nerve. To avoid the risk of the neural injury, several alternative surgical methods have been developed. The endomeatal approach is one of the several alternative techniques. We present, along with a review of literatures, a case of cochlear implantation using the endomeatal approach performed in a child with an extremely hypoplastic mastoid.

Korean J Otorhinolaryngol-Head Neck Surg 2016;59(5):402-5

Key Words Cochlear implantation · Congenital aural atresia · Endomeatal approach.

\section{서 론}

현재 전 세계적으로 널리 사용되는 인공와우이식의 술식은 1961년 House ${ }^{1)}$ 에 의해 고안되었으며, 이는 유양동 삭개술 후 안면신경와에 후고실 개방술을 시행하여 정원창을 노출시키 고 와우개창술을 시행하여 전극을 삽입하는 수술 방식이다. 후고실 개방술을 이용한 이 술식은 와우 기저부의 고실계를 직접 노출시키기 때문에 와우 골화나 섬유화로 인한 병적 구 조물을 확인할 수 있게 해주며, 전극 삽입시 와우 기저 회전 의 진행 방향을 따라 전극을 삽입하기 용이하여 와우 내부 구조의 손상을 최소화할 수 있는 장점이 있어 많은 이과 술자 들이 선호한다. ${ }^{2)}$ 하지만, 이 수술 방법은 유양동 함기화가 매 우 불량하거나 안면신경 주행에 변이가 있는 경우 등에는 적 용이 어려울 수 있다. ${ }^{3)}$

저자들은 선천성 외이도 폐쇄증과 내이기형을 동반한 난청 아동에서 고전적 수술 방법을 적용하기 어려워 경외이도 접근 법을 이용한 인공와우 이식수술을 성공적으로 시행한 사례를

경험하였기에 보고하는 바이다.

증 례

2세 6개월된 여아가 소리에 대한 반응이 없어 본원에 내원 하였다. 과거력에서 심실중격결손, 동맥관 개존증, 미숙아 망 막증, 구개열의 병력과 함께 인지장애가 동반되어 있었다. 신 체검사에서 좌측 선천성 안면마비가 House-Brackman grade III로 존재하였고, 양측 소이증(Marx 분류 IV형)과 양측 외이 도 협착증이 있었다(Fig. 1). 클릭음을 이용한 기도 및 골도 청 성뇌간반응 검사에서 최고 강도 음 자극에도 반응이 나타나 지 않았고, 말언어평가에서 Ling 6 sound 감지 불가능, categories of auditory performance(CAP) score 1, 4 5개월 수준 의 수용 언어 및 표현 언어 능력을 보여 언어발달 지연이 있었 다. 측두골 전산화단층촬영에서는 양측 외이도가 매우 좁은 Schuknecht 분류 A형의 외이도 폐쇄증이 있었고, 양측 유양 동은 거의 발달되지 못한 상태였다. 와우는 정상 모양이었으나 


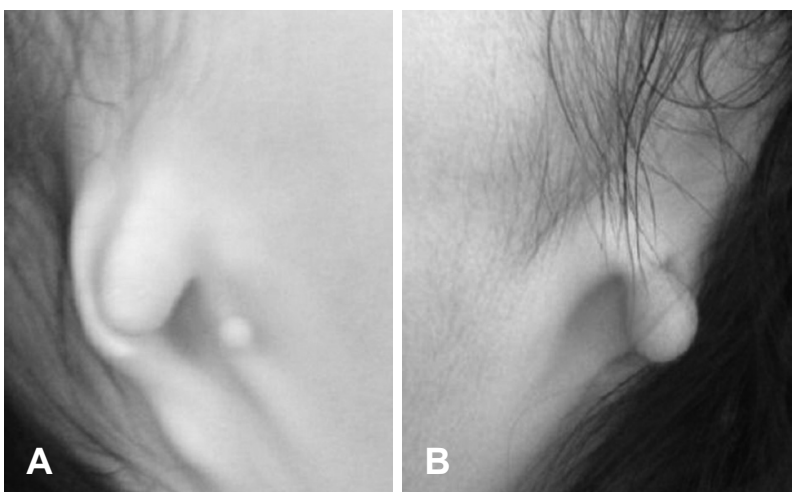

Fig. 1. The photographs of both ears. The child has microtia and aural atresia at both ears. Right ear (A). Left ear (B).
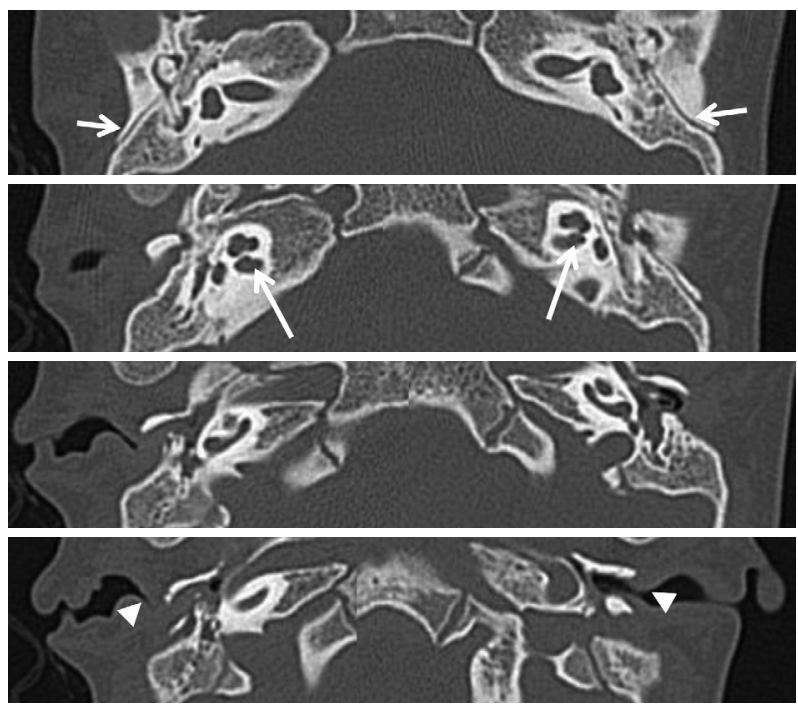

Fig. 2. Axial scans of temporal bone computed tomography. Mastoid pneumatization is lack (short arrows) and external auditory canals of both ears are very stenotic (arrowheads). Cochlear morphology is normal. However right cochlear nerve canal is obliterated and left canal is stenotic (long arrows). Superior and lateral semicircular canals of both ears are aplastic.

와우신경관(cochlear nerve canal)은 우측은 폐쇄되어 있고 좌측은 매우 좁았으며, 전세반고리관과 측세반고리관이 양측 모두 형성되지 않은 상태였다(Fig. 2). 자기공명영상에서는 양 측 모두 와우신경이 확인되지 않았으나 좌측 내이도 내부에 하나의 신경이 확인되었고, 양측 소뇌교각부에 현저한 낭성병 변이 소뇌를 압박하는 소견을 보였다(Fig. 3).

골도 보청기 장착 후 집중적인 청각 재활 치료를 시행하였 으나 말언어 발달에 진전이 없어 인공와우이식을 계획하였 다. 우측 귀는 와우신경관 폐쇄와 와우신경 및 8번 뇌신경 무 형성증으로 판단하여 인공와우이식 대상에서 제외하였다. 반 면 좌측 귀는 와우신경관이 좁지만 열려 있었고, 내이도 내 부에 하나의 신경이 주행하는 소견을 보여 좌측 귀를 이식 귀로 선택하였다.

인공와우이식은 4세 6개월에 CONCERTO(MED-EL,
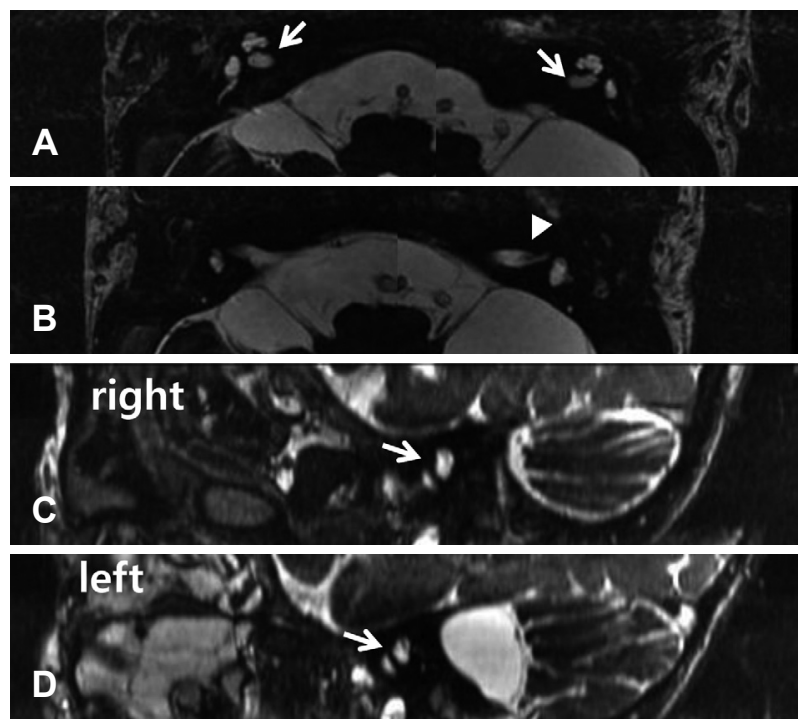

Fig. 3. Magnetic resonance images of internal auditory canal $(A$ and $B$ : axial images, C: right parasagittal image, D: left parasagittal image). Both cochlear nerves are absent (arrows). There is a single nerve in left internal auditory canal (arrowhead).

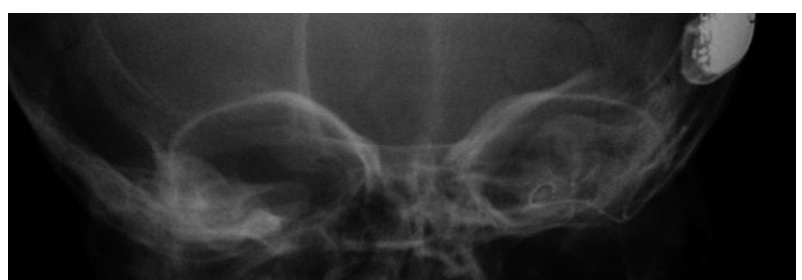

Fig. 4. Postoperative transorbital view. Electrode array is well positioned in left cochlea.

Innsbruck, Austria) 기기를 이용하여 시행하였다. 영상검사에 서 유양동 함기가 매우 불량하여 유양동 삭개술과 후고실 개 방술을 이용하는 고전적인 수술은 불가능하다고 판단하여 경 외이도 접근법을 시도하기로 하였다. 후이개 절개를 가한 후 외이도 피부와 고막을 추골과 함께 제거하였다. 이때 외이도 피부를 거상하면서 동시에 협소한 외이도 골부를 드릴로 삭개 하여 외이도를 확장하여 중이로 향하는 시야를 확보하였고, 외이도 피부를 완전 제거한 후 외이도 입구는 이중 결찰하여 폐쇄하였다. 외이도 후벽에 인공와우의 전극이 위치할 수 있 도록 외이도 입구부에서 고실륜에 이르기까지 너비 $2 \mathrm{~mm}$, 깊 이 $2 \mathrm{~mm}$ 정도의 골(groove)을 만들고, 두정골에 수용자극기 가 위치할 수 있는 함몰부(well)를 만들었다. 중이 점막을 제 거하고 이관입구를 bone wax와 연부조직을 이용하여 폐쇄 하였으며, 정원창의 전상방에 와우개창술을 시행하였다. 수 용자극기를 두정골의 함몰부에 위치시키고 비흡수사를 이용 하여 고정하였으며, 전극은 외이도를 경유하여 와우 내로 삽 입하였다. 중이와 외이도 공간은 복부지방을 이용하여 폐쇄하 고 절개부위를 봉합하여 수술을 마쳤다(Fig. 4). 어음처리기는 수술 후 4 주째 장착하였다. 이개가 없어 귀걸이형 어음처리기 
를 사용할 수 없기 때문에 일체형 어음처리기인 $\mathrm{RONDO}^{\circledR}$ speech processor(MED-EL)를 이용하였다(Fig. 5).

술 후 3 개월에 시행한 말언어 평가에서 CAP score 1, MAIS 3,8 9개월 수준의 수용 언어 능력을 보였다. 술 후 16 개월에

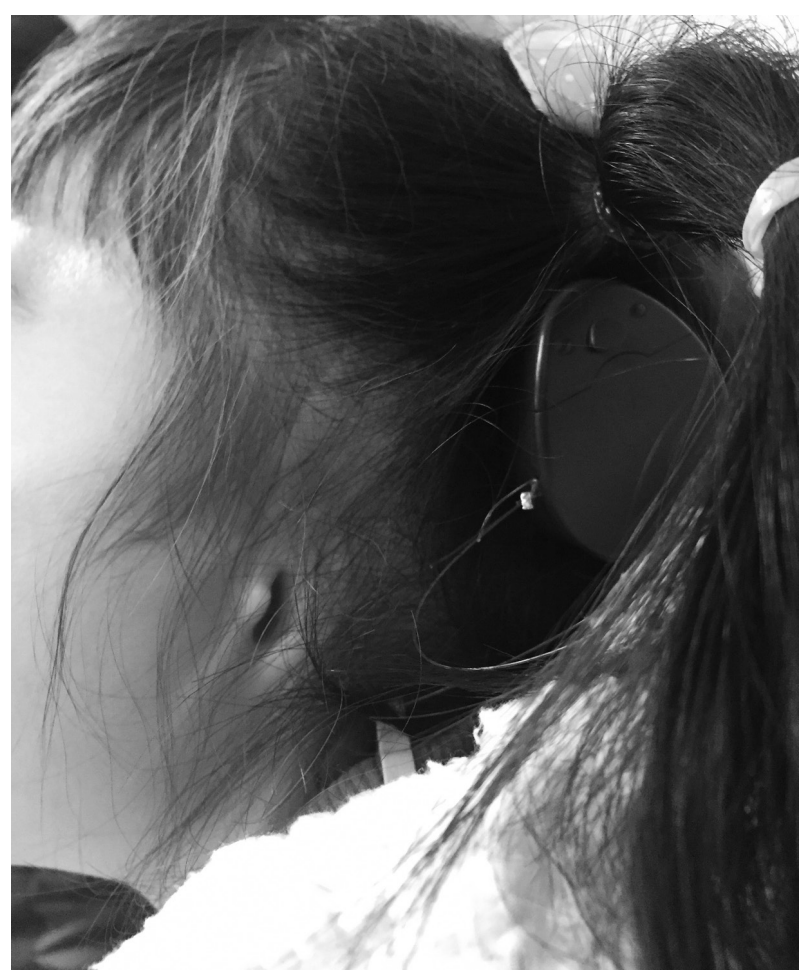

Fig. 5. A single-unit speech processor $\left(\operatorname{RONDO}^{\circledR}\right)$ was used because she did not have an auricle.

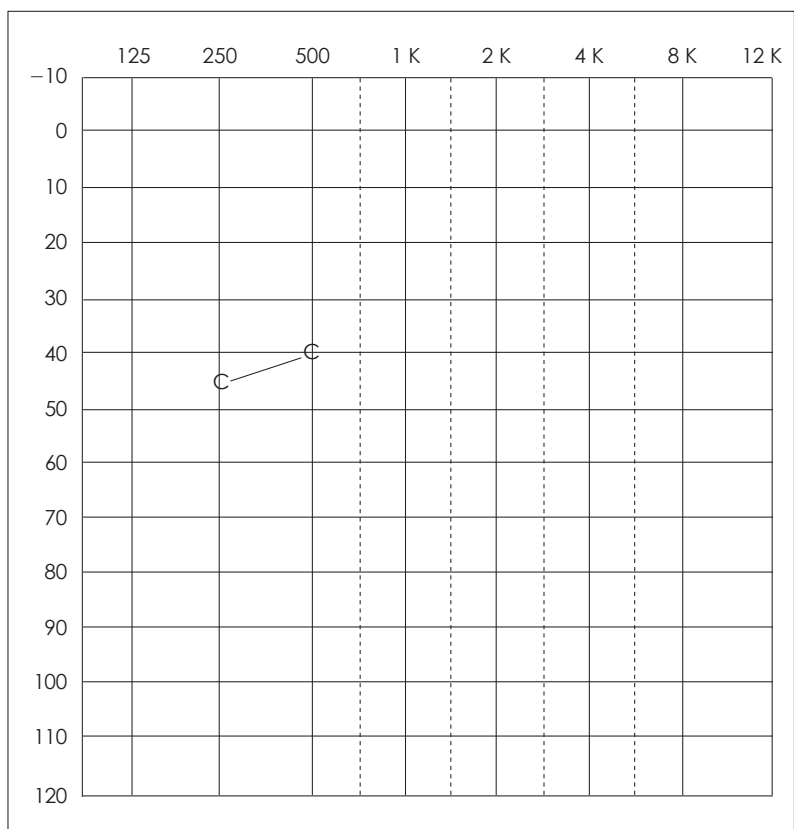

Fig. 6. Pure tone audiogram obtained 16 months after left cochlear implantation. Hearing thresholds with cochlear implant are 45 $\mathrm{dB} \mathrm{HL}$ at $250 \mathrm{~Hz}$ and $40 \mathrm{~dB} \mathrm{HL}$ at $500 \mathrm{~Hz}$.
는 Ling 6 sound 검사의 6가지 소리를 모두 감지하였고, CAP score 2, MAIS 8로 향상되었고, 시각 강화 청력 검사에서 인 공와우 착용 시 청력역치는 $40 \mathrm{~dB} \mathrm{HL}$ 로 측정되었다(Fig. 6).

\section{고 찰}

인공와우 이식수술이 시행된 초기에 수술의 가장 중요한 점 중 하나는 안면신경과 고삭신경의 손상 없이 와우에 접근 하는 것이었다.,5,7) 이후 1993년 Lehnardt ${ }^{8)}$ 에 의해 soft surgery 의 개념이 도입되면서 인공와우 이식수술을 시행할 때 와우 내부 구조의 손상을 최소화하기 위한 노력들이 있어 왔다.3) 인 공와우 이식수술에서 soft surgery의 개념에는 와우 손상을 최소화하는 와우개창술과 부드럽고 세심한 전극의 삽입을 통 한 잔존 청력의 유지가 포함되어 있다. ${ }^{3)}$ 인공와우 이식수술에 서 이러한 여러 가지 요구 사항을 만족시키며 최근까지 가장 널리 사용되고 있는 방식은 House에 의해 고안된 유양동 삭 개술과 후고실 개방술을 이용한 수술법이며, 과거 문헌에 따 르면 대부분의 사례에서 이 고전적인 술식이 안전하고 성공적 인 접근법으로 알려져 있다.,5,7) 하지만 이 술식을 사용할 경 우 안면신경과 고삭신경의 손상이 발생하는 사례가 지속적으 로 보고되어 왔다. ${ }^{4-6)}$ 이에 2000년대 초반부터 안면신경 손상 의 위험을 줄이기 위해 후고실 개방술을 시행하지 않는 Veria operation,' suprameatal approach, ${ }^{2)}$ endomeatal approach ${ }^{9)}$ 등이 고안되었다. 이 방식들의 공통점은 유양동 삭개술과 후 개실 개방술을 시행하지 않으며, 외이도를 통해 전극을 삽입 한다는 점이다. 세 가지 술식의 차이점은 전극이 중이 내부로 접근하는 방법이 조금씩 다르다는 점이다. Veria operation은 Henle spine 후상방, 즉 좌측 귀를 기준으로 할 때 외이도의 1 시 방향에 드릴을 이용하여 구멍을 뚫고 이를 연장하여 중이 까지 통하는 터널을 만드는 방법이다. 드릴이 외이도 후벽을 따라 진행할 때 드릴의 음영이 비춰 보일 수 있도록 외이도 후 벽을 계란 껍질 정도로 얇게 유지해야 하는데, 이 때문에 자

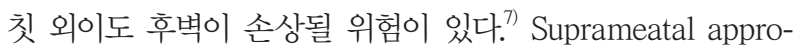
ach도 Henle spine 후상방에 구멍을 뚫어 중이까지 터널을 만드는 방식으로, Veria operation과의 차이는 중두개와 경막 밑에 사선방향으로 터널을 형성하여 전극을 중이까지 접근 시 킨다는 점이다. 이는 일종의 blind surgery 방식이기 때문에 혈관이나 뇌 손상이 발생할 위험성이 있다. ${ }^{2)}$ Endomeatal approach는 터널을 만들지 않고 외이도 후벽을 직접 보면서 드릴 로 골(groove)을 만들어 전극의 통로를 형성한다는 점에서 앞 서 언급한 두 가지 술식에 비해 안전하다. 그러나 외이도 피부 피판과 전극이 닿게 되면 피부 피판 괴사나 고막 천공이 발생 할 수 있는 위험성이 있다. ${ }^{9}$ 
위에 언급된 접근 방식 외에도 유양동 삭개술 없이 와우에 접근할 수 있는 방법으로 Colletti 등미이 중두개와 접근법 (middle fossa approach)을 소개하였다. 이 술식은 와우 골화 가 심할 경우 전극을 와우 첨부에서부터 삽입하는 데 이용될 수 있으나, 수술이 어렵고 수술 시간이 길어 보편적으로 사용 되지는 않는다.

본 증례의 난청 아동은 측두골 전산화단층촬영에서 유양 동이 거의 형성되어 있지 않아 고전적인 방법으로는 인공와우 이식수술이 어려울 것으로 판단하여, 외이도를 통해 와우에 접근할 수 있는 endomeatal approach를 시행하였다. Endomeatal approach는 2002년 Häusler ${ }^{9)}$ 가 처음 소개하였고, 이 후에 조금씩 변형된 형태로 발표되었다. Slavutsky와 Nicenboim $^{11)}$ 은 35 개의 측두골을 이용한 연구 결과를 보고하였는 데, endomeatal approach를 이용하면 정원창을 통하여 전극 을 삽입할 때 고전적인 수술 방법에 비해 보다 나은 입사각을 제공하여 더 부드럽고 자연스럽게 전극을 와우 내로 삽입할 수 있어 soft surgery에 더 적합하다고 하였다. 또한 이 술식을 적용할 경우 정상적으로 기능하고 있는 유양동을 보존할 수 있는 장점이 있다. ${ }^{2}$ 만일 유양동에 염증이 있을 경우 고전적 술식을 적용하면 전극을 통해 와우 내로 염증이 파급될 수 있 어 endomeatal approach가 대안이 될 수도 있다.)

고전적인 수술 방식에 비해 endomeatal approach가 가지 는 단점도 고려해야 한다. 전술한 바와 같이 외이도 피부 피 판과 전극이 서로 접촉하게 되면 피부 피판 괴사로 인한 전극 노출이나 고막 천공이 발생할 가능성이 높다. ${ }^{9}$ Endomeatal approach를 적용하면 유양동 삭개술과 후고실 개방술을 시 행하지 않으므로 수술이 빠르고 쉬운 장점이 있으나, 숙련된 술자에게는 endomeatal approach가 더 간편하다고 할 수 없 고, 수술 시간에 있어서도 큰 차이가 없다. 한 보고에 따르면 고전적인 방식을 이용하여 인공와우 이식수술을 처음 시행할 경우 평균 300 분이 소요되나 4년간의 학습 기간 후 약 100 분 으로 수술 시간이 단축되며, endomeatal approach는 숙련도 에 관계없이 약 100 분의 수술 시간이 소요된다고 하였다. ${ }^{3)}$ 또 한 endomeatal approach를 이용할 경우 고전적인 수술 방식
에 비해 합병증 발생률이 낮다는 보고들이 있지만, 근거가 될 수 있는 수술 사례가 적고 추적관찰 기간이 짧아 단언하기 어 렵다. $2,6,7,11$

결론적으로 endomeatal approach는 인공와우 이식수술을 위한 하나의 유용한 술식으로 적용될 수 있다. 특히 유양동 발달이 매우 불량하거나 안면신경의 주행이상 등으로 인해 유양동을 통한 고전적인 수술 방식을 적용하기 어려운 경우 에 endomeatal approach는 좋은 대안이 될 수 있으므로 인공 와우이식 술자들은 이 수술 방식을 숙지할 필요가 있다.

\section{REFERENCES}

1) House WF. Cochlear implants. Ann Otol Rhinol Laryngol $1976 ; 85$ suppl 27(3 Pt 2):1-93.

2) Kronenberg J, Baumgartner W, Migirov L, Dagan T, Hildesheimer M. The suprameatal approach: an alternative surgical approach to cochlear implantation. Otol Neurotol 2004;25(1):41-4; discussion 44-5.

3) Postelmans JT, Grolman W, Tange RA, Stokroos RJ. Comparison of two approaches to the surgical management of cochlear implantation. Laryngoscope 2009;119(8):1571-8.

4) Cohen NL, Hoffman RA. Complications of cochlear implant surgery in adults and children. Ann Otol Rhinol Laryngol 1991;100 (9 Pt 1):708-11.

5) Cohen NL. Medical or surgical complications related to the nucleus multichannel cochlear implant. Ann Otol Rhinol Laryngol 1989;98 (9):754.

6) Webb RL, Lehnhardt E, Clark GM, Laszig R, Pyman BC, Franz BK. Surgical complications with the cochlear multiple-channel intracochlear implant: experience at Hannover and Melbourne. Ann Otol Rhinol Laryngol 1991;100(2):131-6.

7) Kiratzidis T, Iliades T, Arnold W. Veria Operation. II. Surgical results from 101 cases. ORL J Otorhinolaryngol Relat Spec 2002;64(6):413-6.

8) Lehnhardt E. [Intracochlear placement of cochlear implant electrodes in soft surgery technique]. HNO 1993;41(7):356-9.

9) Häusler R. Cochlear implantation without mastoidectomy: the pericanal electrode insertion technique. Acta Otolaryngol 2002;122(7): 715-9.

10) Colletti V, Fiorino FG, Carner M, Pacini L. Basal turn cochleostomy via the middle fossa route for cochlear implant insertion. Am J Otol 1998;19(6):778-84.

11) Slavutsky V, Nicenboim L. Preliminary results in cochlear implant surgery without antromastoidectomy and with atraumatic electrode insertion: the endomeatal approach. Eur Arch Otorhinolaryngol 2009; 266(4):481-8. 